\title{
123622
$p-22$
}

\section{Ceramic Component Reliability With the Restructured NASA/Cares Computer Program}

Lynn M. Powers

Cleveland State University

Cleveland, Ohio

and

Alois Starlinger and John P. Gyekenyesi

Lewis Research Center

Cleveland, Ohio

Prepared for the

37th International Gas Turbine and Aeroengine Congress sponsored by the American Society of Mechanical Engineers

Cologne, Germany, June 1-4, 1992 


\title{
CERAMIC COMPONENT RELIABILITY WITH THE RESTRUCTุURED NASA/CARES
}

COMPUTER PROGRAM

\author{
Lynn M. Powers \\ Cleveland State University \\ Department of Civil Engineering \\ Cleveland, Ohio 44115 \\ Alois Starlinger ${ }^{* *}$ and John P. Gyekenyesi \\ National Aeronautics and Space Administration \\ Lewis Research Center \\ Cleveland, Ohio 44135
}

\section{SUMMARY}

The Ceramics Analysis and Reliability Evaluation of Structures (CARES) integrated design program on statistical fast fracture reliability of monolithic ceramic components is enhanced to include the use of a neutral data base, two-dimensional modeling and variable problem size. The data base allows for the efficient transfer of element stresses, temperatures and volumes/areas from the finite element output to the reliability analysis program. Elements are divided to insure a direct correspondence between the subelements and the Gaussian integration points. Two-dimensional modeling is accomplished by assessing the volume flaw reliability with shell elements. To demons:rate the improvements in the algoritnm, example problems are selected from a round-robin conducted by WELFEP (WEakest Link failure probability prediction by Finite Element Postprocessors).

\section{INTRODUCTION}

Advanced gas turbine technologies require materials that exhibit low density, good oxidation and corrosion resistance, high specific strength and stiffness, all at high temperatures. Selected structural ceramics exhibit these desirable material properties. Thus, improvements in fuel efficiency are anticipated due to increased engine temperatures and pressures, which in turn generate more power and thrust. Progress in utilizing advanced gas turbines has also supported cogeneration technologies. The use of monolithic ceramics as structural materials has been limited by their inherent brittleness, susceptibility to damage from thermal shock, and a large variation in strength which is reflected in diminished component reliabilities.

Thus, analyses of components fabricated from ceramic materials require a departure from the usual deterministic design philosophy (i.e., the factor of safety approach) prevalent in analyzing metallic structural components. For this reason, the integrated design program CARES (Ceramics Analysis and Reliability Evaluation of Structures) has been developed at NASA Lewis Research Center (Nemeth et al., 1990). In the CARES program, a probabilistic approach is adopted that allows the design engineer to account for variability in strength and diminished load capacity with increasing component size (the 8ocalled size effect). The goal is to predict the time-independent reliability of a structural component subjected to multiaxial load conditions. Volume and/or surface flaws can be taken into account. Weibull

\footnotetext{
"NASA Resident Research Associate at Lewis Research Center.

** National Research Council-NASA Research Associate at Lewis Research Center.
} 
material strength parameters, the Batdorf crack density coefficient, and other related statistical quantities can be estimated from bend bar or uniaxial tensile specimen fracture strength data.

The structural response of isotropic components subjected to thermomechanical loads is usually determined by commercial finite element programs. These finite element programs must be coupled to CARES for evaluation of the structural reliability for a component. The first version of CARES has proven its applicability in the design of gas turbine rotors, uncooled combustors, engine exhaust valves, laser windows on test rigs, and spacecraft activation valves.

Currently, a next generation algorithm, CARES 3.0, has been developed that allows the design engineer access to additional finite element programs through the use of a formatted neutral data base. The algorithm is split into two separate modules: (1) the finite element data interface program, and (2) the reliability evaluation algorithm. In the first module, results from finite element analysis (available in the form of standard output files and/or plot data files) are interpreted. The finite element data is written to a neutral data base containing element or subelement stresses, volumes (or surface areas for shell elements), and temperatures. At this time, CARES 3.0 is coupled to the MSC/NASTRAN and ABAQUS general purpose finite element packages, and interfaces with ANSYS and MARC are being planned.

In the second module, CARES 3.0 reads this data base for the reliability analysis. In the reliability evaluation algorithm a modular structure is used. The main program subsequently calls special subroutines for reading the control file, calculating and/or storing the material parameters, printing the input data, reading the neutral data base, calculating risk of rupture intensities (a local measure of reliability) and probability of failure, creating a PATRAN element file, and printing the results. This modular structure will make the implementation of future changes and additions, such as more sophisticated failure models, easier without undertaking extensive programming efforts.

Furthermore, a subelement technique has been implemented. In a previous version, CARES2, the element stress tensor was obtained by averaging the stress state at each node over the entire element. The nodal stress tensor was computed by extrapolating the stresses from the integration points, and as a consequence, the stress state could only be approximated. This results in a lack of accuracy in problems where high stress gradients exist over the element.

In the subelement technique the reliability function is applied at each Gaussian integration point instead of using averaging techniques. This approach is now feasible since all commercial analysis programs make integration point stresses and temperatures available, although the current release of MSC/ NASTRAN (version 66) has an error retrieving these stresses. Consequently we had to interpolate nodal stresses when MSC/NASTRAN was used. Thus, considerable improvements in the accuracy of reliability analyses have been realized. To demonstrate the improvements in the algorithm, example problems are selected from a round-robin conducted by WELFEP (WEakest Link failure probability prediction by Finite Element Postprocessors). This group includes researchers from Europe and the United States who are involved in the implementation of postprocessors for reliability prediction. The goals of this study are to compare and verify postprocessors and to formulate guidelines for their implementation and use. Initial comparisons will be based on the results of the round-robin calculation which consists of three test
cases.

\section{RELIABILITY MODELS}

A complete description of the failure models used in CARES was given by Nemeth et al. (1989) and (1990). These models which describe the statistical nature of fracture in brittle materials are based 
on the weakest-link theory and the two-parameter Weibull distribution (Weibull, 1939a). Concepts developed by Batdorf (Batdorf and Crose, 1974) provide the physical foundation for use of various failure criteria by incorporating linear elastic fracture mechanics into weakest-link theory to account for the effects of multiaxial stress states.

The WELFEP study examines the principle of independent action (PIA) (Barnett et al., 1967; and Freudenthal, 1968), and the Weibull normal stress averaging method (Weibull, 1939b). For the PIA model, the probability of failure for volume flaws, $P_{f v}$, is expressed as

$$
P_{f v}=1-\exp \left[-\frac{1}{\sigma_{\sigma v}^{m}} \int_{V}\left(\sigma_{1}^{m}+\sigma_{2}^{m_{V}}+\sigma_{3}^{m_{V}}\right) d V\right]
$$

and for surface flaws, $P_{f b}$

$$
P_{G}=1-\exp \left[-\frac{1}{\sigma_{o t}^{m_{1}}} \int_{A}\left(\sigma_{1}^{m_{1}}+\sigma_{2}^{m_{1}}\right) d A\right]
$$

where $m$ is the Weibull modulus and $\sigma_{0}$ is the scale parameter, whose units are stress $\times$ length ${ }^{3 / m}$ for $\sigma_{\text {ov }}$ and stress $\times$ length ${ }^{2 / m}$ for $\sigma_{o s}$. The subscripts $v$ and $s$ denote volume and surface flaw analysis, respectively. The principal stresses are represented by $\sigma_{1}, \sigma_{2}$ and $\sigma_{3}, V$ is the volume and $A$ is the surface area.

In the normal stress averaging method (shear insensitive), the probability of failure for volume flaw analysis is given by

$$
P_{f v}=1-\exp \left[-k \int_{v} \vec{\sigma}_{\mathrm{i}} \mathrm{dV}\right]
$$

and for surface flaws,

$$
P_{f_{3}}=1-\exp \left[-\mathbf{k}_{\mathbf{2}} \int_{\mathbf{A}} \overrightarrow{\sigma_{\mathbf{m}}} \mathbf{d A}\right]
$$

where $\mathbf{k}$ is the normalized polyaxial Weibull crack density coefficient and $\bar{\sigma}_{n}$ is the average normal stress. The normalized polyaxial Weibull crack density coefficient is obtained by applying the normal stress averaging method to a uniaxial stress state, and by equating that result with the uniaxial twoparameter Weibull equation. For volume flaws, $k_{\mathbf{v}}$ is given by

$$
k_{v}=\left(2 m_{v}+1\right) \frac{1}{\sigma_{o v}^{m}}
$$

and for surface flaws 


$$
k_{1}=\left[\frac{m_{1} \Gamma\left(m_{z}\right) \sqrt{\pi}}{\Gamma\left(m_{z}+\frac{1}{2}\right)}\right] \frac{1}{\sigma_{\infty}^{m_{3}}}
$$

The normal stress is averaged on the surface of a unit sphere for volume flaws. Analogously, the line integration is performed over the contour of a unit radius circle for surface flaws. The symmetry of the stress reduces the integration to an eighth of the sphere and a quarter of the circle (Nemeth et al., 1990).

The shear-sensitive models available in CARES are based on concepts developed by Batdorf and Crose (1974). They require a user-selected flaw geometry and a mixed-mode fracture criterion. Flaws intersecting the surface can be modeled as Griffith cracks, Griffith notches, or semicircular cracks. Imperfections embedded in the volume can be described as Griffith flaws, Griffith cracks, or penny-shaped cracks. The total strain energy release rate theory is used as a mixed-mode fracture criterion for coplanar crack extension (Batdorf and Heinisch, 1978). Out-of-plane crack extension criteria are approximated by an equation with a semiempirical constant (Palaniswamy and Knauss, 1978; Shetty, 1987) that models various crack configurations and fracture theories such as the maximum tangential stress (Erdogan and Sih, 1963), the maximum strain energy density criterion (Sih, 1974), and the maximum strain energy release rate criterion (Hellen and Blackburn, 1975).

\section{PROGRAM FEATURES}

Based on the previous version of CARES (Nemeth et al., 1990), which was coupled to MSC/ NASTRAN and ANSYS stress analyses, a next generation algorithm has been developed that allows access to additional finite element programs through the use of a formatted neutral data base. In the following section, the new features of CARES will be highlighted in comparison to the previous version. The original algorithm has been reorganized into the following separate modules:

1. Finite element data interface

2. Reliability evaluation algorithm.

The interface program interprets the data necessary for subsequent reliability analysis, and translates this information into a formatted (ASCII) neutral data base. This feature enables easy data transfer between different computer systems. The reliability evaluation algorithm performs the computations necessary in
determining structural reliability.

Furthermore, a subelement technique has been implemented. The reliability analysis is now performed at each Gauss integration point instead of using element averaging techniques. In the context of finite element analysis, stresses are determined at the Gaussian integration points where the local stiffness matrix has been evaluated. The subelement technique implies that each Gaussian integration point corresponds to a subelement. The subelement volume is defined as the contribution of the integration point to the element volume in the course of the numerical integration procedure.

The location of the Gaussian integration point in the natural space of the finite element, as well as corresponding weight functions have to be considered when the subelement volume is calculated. For this reason, the number of subelements in each element depends on the integration order chosen, and as a consequence, the element type. The increased number of points for stress evaluation accounts for the variation in stress over the element. Thus, considerable improvements in the accuracy of the reliability analysis have been realized (the reader is referred to the numerical examples that follow). 
Due to this subelement concept a new global structure of the algorithm has evolved. The modular structure of the program readily allows future changes and additions without undertaking large programming efforts. This version of CARES also allows variations in temperature throughout the structure. CARES 3.0 is programmed in standard FORTRAN77. This allows easy implementation on numerous computer systems. The introduction of one large blank common array (instead of several fixed-dimension arrays) in each routine allows the user to easily adapt the program to the problem size as well as to the available computational resources. The adaption of the size of the blank common array can readily be adjusted by resetting one parameter at the beginning of the program (MTOT). In contrast to previous versions of CARES the code can now also be implemented on PC systems. The reliability evaluation algorithm requires two input files, a control file and a neutral data base. The control file defines the number of different materials, the temperature dependent Weibull parameters and flags for printing and postprocessing (e.g., writing the element risk of rupture intensities to a PATRAN data file). These parameters are stored in the blank common array.

The finite element results and data required for the reliability analysis are supplied by the neutral data base, including the stress tensors and temperatures at the integration points. The structure of the neutral data base is optimized with respect to memory. The finite element data is arranged within the neutral data base using the following hierarchy, element groups, elements and subelements. The element group data contain information regarding the number of elements within the group. In addition to the element types available in the previous version of CARES (three-dimensional brick elements for volume flaw analysis, membrane elements for surface flaw analysis), two-dimensional finite elements are also implemented. By assuming plane stress conditions or exploiting symmetry of the structure, the size of the finite element model can be reduced using a two-dimensional mesh. Thus, the number of degrees of freedom covld be substantially reduced.

The two-dimensional modeling options available (in plane loading versus bending) depend on the method used to determine the volume. In the case of MSC/NASTRAN, the volume is calculated by multiplying the area of a subelement (see NEUTRAL DATA BASE CONCEPT) by the thickness of the element. Therefore, bending effects are not taken into account because the stress is assumed to be constant through the thickness.

Information pertaining to the elements include the number of subelements and the material identification number. Finally, the subelement group data contains information regarding subvolume, stress tensor (i.e., the stress tensor at the integration point), and subelement temperature. The stresses and temperatures are assumed to be constant over the subelement considered.

Depending on the size of the finite element mesh (number of element groups, elements and subelements in the finite element model) pointers are calculated for the blank common array, and the corresponding size limits are checked. As the stresses are transformed to principal stresses immediately after reading the stress tensor at the subelement level, the required memory is optimized. Only the principal stresses in each subelement, the subelement volume (area in the case of shell elements), the subelement temperature, the material identification number for the considered element and the element thickness (only for shell subelements) have to be stored.

To take into account variations in the temperature field, the Weibull parameters are calculated by linear interpolation between the temperature dependent parameters entered in the control file. In CARES2, the temperature dependent material parameters were calculated by Lagrangian polynomials, but this algorithm did not work properly for special data configurations. 
After performing the reliability analysis, the element risk of rupture data (a local measure of reliability) can be written into a PATRAN element file. This procedure allows visualization of critical regions in the structure (only available, if the finite element mesh has been generated via PATRAN preprocessing). For a subelement over which the state of stress and temperature are assumed to be constant, the reliability is expressed as

$$
\mathbf{R}_{\mathbf{i}}=\exp \left[-\varphi_{\mathbf{i}} \mathbf{V}_{\mathbf{i}}\right]
$$

where $R_{i}$ is the reliability, $\varphi_{i}$ is the risk of rupture intensity and $V_{i}$ is the volume of the i'th subelement. The reliability of the component is determined by the product of all individual subelement reliabilities or

$$
R=\prod_{i=1}^{k} R_{i}=\exp \left[-\sum_{i=1}^{k} \varphi_{i}^{\infty \omega} V_{i}^{\infty \omega}\right]
$$

The risk of rupture intensity for an element, $\varphi_{l}^{\text {do }}$, is a weighted average of the intensities of the subelements or

$$
\varphi_{i}^{a b}=\frac{\sum_{j=1}^{n} \varphi_{j}^{a b} V_{j}^{m b}}{\sum_{j=1}^{n} V_{j}^{m b}}
$$

where $\mathbf{n}$ is the number of subelements within the element. For shell elements (surface flaws) the volume is replaced by an area term. The risk of rupture intensity, $\varphi_{i}^{\text {do }}$, is only used for PATRAN postprocessing.

\section{NEUTRAL DATA BASE CONCEPT}

The concept of a formatted neutral data base allows for the interfacing of CARES 3.0 to several finite element packages. The results from the finite element analysis (available in the form of standard output files and/or plot data files) have to be interpreted by an interface program. Due to the different formats used for output of the results in each finite element program this interpreter program has to be adapted to the finite element software used. The interface programs for NASTRAN and ABAQUS have already been implemented, interfaces for MARC and ANSYS are being prepared.

The finite element results required for the reliability estimation are assembled into the formatted neutral data base. A further advantage of this approach is the ease of transfer of this formatted neutral database (ASCII file) to different computer systems. Interpreter control parameters, such as the number of element groups to be considered in the reliability analysis, flags for accounting for temperature field gradients, etc., are usually input via an interpreter control file.

The introduction of comment lines (defined by "COM" as the first three characters of an input line) allows for a more friendly substructuring of the neutral data base. Based on the global hierarchy outlined 
above, the neutral file data is arranged into records with standard FORTRAN formats: the first record (format A80) specifies the title for the particular reliability evaluation. The next entry (format 2I5) contains the number of element groups NUMEL (both volume as well as surface (shell) elements) to be considered in the reliability analysis and the flag NUMELB indicating combined volume as well as surface flaw reliabillty analysis for shell elements.

Depending on the parameter NUMEL, a loop over all element groups is started with the next statement (format 4I5): the identification number of the element group considered (INUEG), the element type (IEGTYP) corresponding to PATRAN element type codes, the number of elements within this element group (IGREL) and a shell element type indicator (ISHELL) have to be input. If shell elements are used in the analysis, the indicator ISHELL has to be set to 1 . Information pertaining to the element level is read in a loop over the number of elements (IGREL) within the element group considered (format 4I5,3F 15.0).

The element level data contains the identification number of the element considered (IELNUM), the number of subelements within this element (ISUBEL), the material identification number for volume flaw analysis (MATINP), the material identification number for surface flaw analysis (MAT2), the element volume (ELVOL), the element thickness (ELTHIC) only in case of shell elements, and the averaged temperature of this element (ELTEMP). The identification number of the element should be the same as the corresponding element number in the finite element mesh, if further postprocessing of the reliability results are planned. The number of subelements within this element depends on the Gaussian integration order chosen in the finite element analysis and on the element type. If stress data is only available at the center of the element (standard case in NASTRAN analyses prepared for previous CARES versions), one subelement is specified (ISUBEL $=1$ ). The material identification numbers must correspond to the material numbers used in the finite element analysis as well as the material numbers on the control file (containing the Weibull parameters). Element volume and element temperature are necessary only for element group information summaries in the printout file. For the reliability evaluation the subelement data are directly used.

A third loop is started for reading the subelement level data. In case of volume type elements (ISHELL $=0$ on Element Group Entry) the identification number of the subelement (ISUNUM), the subelement volume (SUBVOL), the subelement temperature (SUBTEM) and the full stress tensor at the integration point (defined by $\sigma_{\mathrm{xx}}, \sigma_{\mathrm{yy}}, \sigma_{\mathrm{zz}}, \sigma_{\mathrm{xy}}, \sigma_{\mathrm{yz}}$ and $\sigma_{\mathrm{xz}}$ in the local coordinate system) have to be specified (format $15,5 \mathrm{~F} 15.0, /, 35 \mathrm{X}, 3 \mathrm{~F} 15.0$ ).

In the case of shell type elements (ISHELL $=1$ on Element Group Entry) plane stress conditions are assumed. For that reason only $\sigma_{x x}, \sigma_{y y}$ and $\sigma_{x y}$ are necessary for the definition of the subelement stress tensor. Instead of the subelement volume, the subelement area has to be specified (I5,5F 15.0): ISUNUM, SUBAREA, SUBTEM, $\sigma_{x x}, \sigma_{y y}$ and $\sigma_{x y}$

Typically, subelement volumes are not included with standard finite element output. Thus, the volume of each subelement (corresponding to a Gauss integration point) is calculated in the interpreter program using the shape functions inherent to the element type. In the usual context of finite element methods, the volume of a three-dimensional element, (i.e., brick, wedge, pyramid or tetrahedron) is calculated after transformation into the natural coordinate space (Bathe, 1982),

$$
V=\int_{-1}^{1} \int_{-1}^{1} \int_{-1}^{1} \operatorname{det} J(r, s, t) d r d s d t
$$


where $\mathbf{J}$ is the Jacobian operator and $r, s, t$ are the natural coordinates. By applying a Gaussian integration scheme, the integral can be expressed as

$$
V=\sum_{i=1}^{n} \sum_{j=1}^{n} \sum_{i=1}^{n} \operatorname{det} J\left(r_{i}, s_{j}, t_{k}\right) W_{i} W_{j} W_{k}
$$

where $\mathbf{n}$ is the integration order, $\mathbf{r}_{i}, s_{j}, t_{k}$ are the coordinates of the Gaussian integration points in natural space and the W's are the weight functions. The area of an element (i.e., quadrilateral or triangle) is determined in a similar manner

$$
A=\sum_{i=1}^{n} \sum_{j=1}^{n} \operatorname{det} J\left(r_{j}, s_{j}\right) W_{i} W_{j}
$$

The volume of an axisymmetric element can also be determined similarly

$$
V=R \sum_{i=1}^{n} \sum_{j=1}^{n} \operatorname{det} J\left(r_{i} s_{j}\right) w_{i} W_{j}
$$

where $R$ is the radial coordinate of the integration point in the global coordinate system.

\section{NUMERICAL EXAMPLES}

To demonstrate the improvements in the algorithm, example problems are selected from a roundrobin conducted by the WELFEP group. The first test case is a beam in pure bending. Comparisons with the analytical solution are made to verify convergence and the mathematical correctness of the codes. The second structure is a notched beam in four-point bending. The induced concentration will test the algorithms used to identify element stresses. The final test case is a tube under ideal torsion. Comparisons from this problem verify the manner in which the reliability for multiaxial stress states is determined. For the purpose of this study, two failure models will be examined: the Principle of Independent Action (PIA) and the Normal Stress Averaging method (NSA). Both are based on Weibull's weakest link theory.

To demonstrate the improvements achieved in this version of CARES 3.0, the results of the reliability analysis are compared to the reliability data generated by the previous version of the program (CARES2: subelements are obtained by dividing the element into equal cells, the stresses are interpolated from the nodes.). MSC/NASTRAN finite element analysis is used for each of the test cases. CARES 3.0 is used to determine the reliability for volume and surface flaw analysis. All volumes are meshed with threedimensional elements (CHEXA) and shell elements (CQUAD8) are used for modeling the surfaces (midside nodes are present). Material properties are arbitrarily chosen (the same for each test case: Young's modulus is $300 \mathrm{MPa}$ and Poisson's ratio is 0.2 ).

A description of the beam analyzed in test case number 1 is given in Fig. 1. Bending of the beam is induced by prescribed displacements that are linearly varied at $x=L$. Due to symmetry considerations only one quarter of the beam has to be modeled (as indicated in Fig. 1). In order to study the influence of finite element discretization, linear finite element analyses are performed with a coarse and a fine mesh. The coarse mesh consists of 10 elements along the length direction $(x)$, four in the height direction (y), 
and one element in the thickness direction (z). The fine mesh is similar with 20,8 and one element in the length, height, and thickness directions, respectively. The results of the CARES 3.0 reliability analyses as well as the analytical solution are listed in Table I.

As expected, the solutions for the refined mesh are much closer to the analytical value than the results for the coarse mesh. Comparing the results from CARES 3.0 to the results for the previous version CARES2 shows significant improvements in accuracy. Even in the case of the coarse mesh, the increased number of subelements enables the model to approach the exact solution. The results for the fine mesh nearly coincide with the analytical solution. By modeling the component with a coarse mesh, numerical efforts in finite element analysis can be reduced for preliminary design. The final design is usually checked with a fine mesh.

In Example 2, a notched beam in four-point bending is investigated. Due to the notch, a stress concentration is induced which yields a multidimensional stress field. Symmetry considerations again allow us to reduce the finite element model to one quarter of the original beam (as shown in Fig. 2). In the vicinity of the notch the finite element model is refined to account for the strongly varying stress gradient. The reliability results are listed in Table $\mathrm{I}$. An analytical solution for the reliability is not available. Comparing the results from CARES 3.0 with the results from CARES2 shows that the new version calculates more conservative results for volume flaws, and lower values for probability of failure for surface flaws.

In Example 3, a tube under pure torsion is analyzed. Figure 3 shows the geometry of the tube. Torsional stresses are induced by prescribed displacements at the end of the tube $(z=L)$. Three elements are used in the radial direction, 24 around the circumference, and only one element in the length direction. The results of the reliability analysis are shown in Table I, including the analytical solution of this problem for the PIA model. Again, CARES 3.0 delivers more conservative results than CARES2. The probability of failure data coincides with the analytical solution for the PIA model. To achieve the same degree of accuracy with CARES2, a refined mesh would be necessary. Thus, CARES 3.0 allows considerable reduction in the size of finite element discretizations.

\section{SUMMARY}

Based on the previous version, CARES2, an improved analytical tool has been developed for the reliability evaluation of monolithic ceramic components. By dividing the original program into two separate modules, a greater flexibility is achieved leading to easy integration with various finite element programs. Additionally, the neutral data base concept allows easy data transfer between different computer systems. The modular structure also allows for the incorporation of more sophisticated failure models. CARES 3.0 will serve as the platform for future time dependent analysis.

With the introduction of a new subelement technique, the accuracy of the reliability analyses has improved. In order to achieve the same degree of accuracy, CARES 3.0 allows structural components to be modeled with coarser finite element meshes than what was required by the previous version of the program. Numerical examples demonstrate this feature. 


\section{APPENDIX A}

\section{PREPARATION OF A MSC/NASTRAN PROBLEM FOR RELIABILITY ANALYSIS}

\section{WITH CARES 3.0}

The following describes the necessary information to be included in the MSC/NASTRAN input for further analysis by CARES 3.0. Figure A1 shows the operational flow for the reliability evaluation of ceramic components. This analysis includes the CARES integrated design program, MSC/NASTRAN static finite element analysis and PATRAN PLUS pre- and post-processing. NASCARES interprets MSC/NASTRAN output and assembles it into the neutral file.

The MSC/NASTRAN data file contains three parts: the EXECUTIVE CONTROL, CASE CONTROL and BULK DATA. The following example of the EXECUTIVE CONTROL is typical for a problem involving static analysis;

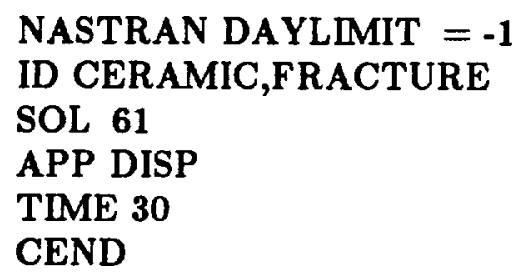

It is assumed that the user is familiar with MSC/NASTRAN, so each statement will not be explained herein. For problems that are modeled with cyclic symmetry, Solution Sequence 61 is replaced by Rigid Format 47.

Previously, Solution Sequence 61 (SUPERELEMENT STATICS or in version 66, SOL 101) and Rigid Format 47 (CYCLIC STATICS) were used for the analysis. These solution methods were employed because element volumes and areas can be obtained through a PARAM card located in the BULK DATA. Since the element (and subelement) volumes/areas are now calculated by NASCARES, there is no longer a limit on solution sequences selection.

For the CASE CONTROL DECK, a typical problem may contain,

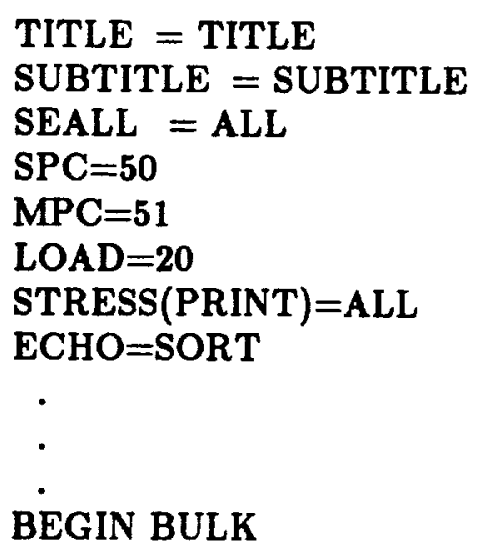

The following three items are important to note. First, multiple load subcases are not defined. CARES 3.0 does not handle stress output from multiple subcases. Therefore, separate NASTRAN executions are 
required for each loading condition. Secondly, element stresses are routed to the printout file when STRESS(PRINT)=ALL; is specified. All element stresses must be placed in the print file. Lastly, ECHO=SORT; will send the sorted BULK DATA to the print file. NASCARES reads the necessary BULK DATA, such as material ID, element connectivities, and nodal temperatures, from the print file. The BULK DATA entries which are processed by NASCARES are listed in table A1.

The PARAM,EST,1 card will output element volumes and areas to the NASTRAN printout file. This card only functions for some solution sequences or rigid formats. The TEMPD card is required if some grid points do not have an explicit temperature assignment. All nodes must have an associated temperature. These are specified with TEMP, TEMP*, or TEMPD card. Since this version of CARES does not examine cards for their subcase identity, caution must be exercised not to allow multiple temperature cases. Nodal temperatures are used by CARES to obtain the average element or subelement temperatures, which are not routinely available in MSC/NASTRAN. The CARES program utilizes results from isoparametric two- and three-dimensional finite elements. A list of the available elements is given in table A2. For typical designs, the three-dimensional HEXA and PENTA elements should be used to model the structure, including thin cross sections such as blades.

After execution of the MSC/NASTRAN problem, the analyst should have a print file containing the sorted BULK DATA, element stresses and general problem information. At this point, all the information required from MSC/NASTRAN to determine the component reliability is present. 


\section{APPENDIX B}

NEUTRAL FILE SETUP

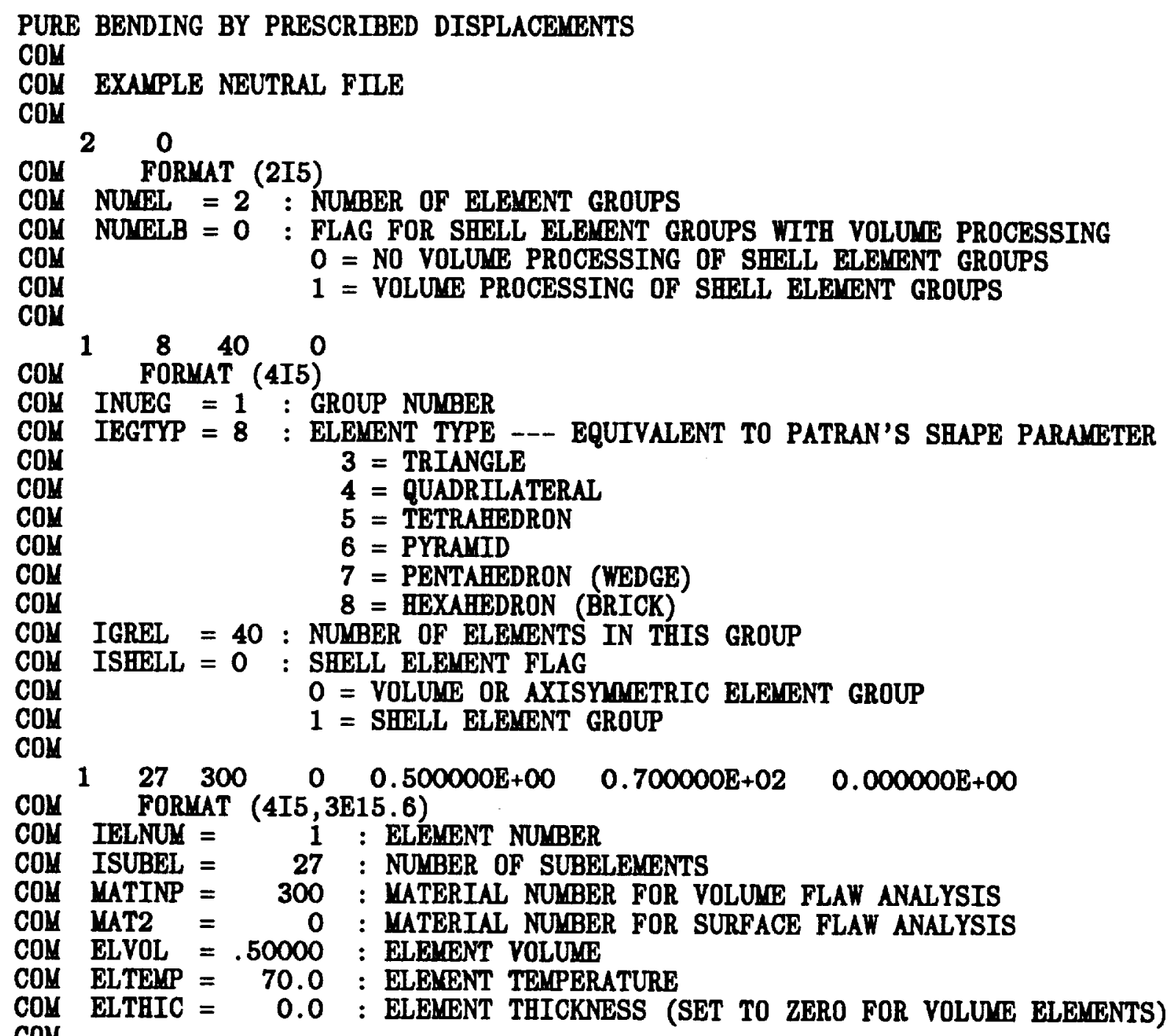

COM

COM

COM

COM

COM

$\begin{array}{lllll}1 & 27 & 300 & 0 & 0.500000 \mathrm{E}+00\end{array}$ $0=$ NO VOLUME PROCESSING OF SHELL ELEMENT GROUPS

COM

COM

COM

COM

COM

COM

COM

COM

$1 \quad 0.107167 \mathrm{E}-01$

$0.700000 \mathrm{E}+02$

$-0.166906 \mathrm{E}+03$ $0.201770 \mathrm{E}-06$

$0.144637 \mathrm{E}-05$

$0.137424 \mathrm{E}-05$

$-0.167879 \mathrm{E}-06$

FORMAT $(\mathrm{I5}, 5 \mathrm{E} 15.6, /, 35 \mathrm{X}, 3 \mathrm{E} 15.6)$

COM ISUNUM $=\begin{gathered}1 \\ \text { : SUBELEMENT NUYBER }\end{gathered}$

COM SUBVOL $=.01072:$ SUBELENENT VOLUNE

COM SUBTEM $=70.0$ : SUBELEMENT TEMPERATURE

$\operatorname{COM} \operatorname{SSTR}(\mathrm{L}), \mathrm{L}=1,6 \quad$ : STRESSES

COM

COM
$2 \quad 0.171468 \mathrm{E}-01$
$0.700000 \mathrm{E}+02$
$-0.166906 \mathrm{E}+03$
$0.718933 E-06$
$3 \quad 0.107167 \mathrm{E}-01$
$0.700000 \mathrm{E}+02$
$-0.166806 \mathrm{E}+03$
$0.123810 \mathrm{E}-05$
$4 \quad 0.171468 \mathrm{E}-01$
$0.700000 \mathrm{E}+02$
$-0.225001 \mathrm{E}+03$
$5 \quad 0.274348 \mathrm{E}-01$
$0.700000 \mathrm{E}+02$
$-0.113103 \mathrm{E}-07$

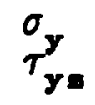

$-0.128449 \mathrm{E}-05$

$-0.108985 \mathrm{E}-05$

$-0.401535 \mathrm{E}-05$

$-0.355393 \mathrm{E}-05$

0.500609E-06

0.451752E-06

$-0.753135 \mathrm{E}-06$
$-0.732417 \mathrm{E}-07$

$-0.536754 \mathrm{E}-06$

$0.213957 \mathrm{E}-07$

$-0.869168 \mathrm{E}-06$

$-0.196162 \mathrm{E}-06$

$-0.104590 \mathrm{E}-06$

$-0.166012 \mathrm{E}-06$ 


\section{$0.179052 \mathrm{E}-07 \quad-0.293684 \mathrm{E}-06 \quad-0.277750 \mathrm{E}-06$}

$\begin{array}{rrlrrrr}25 & 0.107167 \mathrm{E}-01 & 0.700000 \mathrm{E}+02 & 0.169347 \mathrm{E}+02 & 0.780221 \mathrm{E}-01 & 0.234190 \mathrm{E}-01 \\ & & & -0.536288 \mathrm{E}+00 & -0.645437 \mathrm{E}+00 & 0.990120 \mathrm{E}-01 \\ 26 & 0.171468 \mathrm{E}-01 & 0.700000 \mathrm{E}+02 & 0.173446 \mathrm{E}+02 & 0.174948 \mathrm{E}+01 & 0.429904 \mathrm{E}+00 \\ & & & 0.330185 \mathrm{E}+00 & 0.808340 \mathrm{E}+00 & 0.978093 \mathrm{E}-01 \\ 27 & 0.107167 \mathrm{E}-01 & 0.700000 \mathrm{E}+02 & 0.177545 \mathrm{E}+02 & 0.342093 \mathrm{E}+01 & 0.836389 \mathrm{E}+00 \\ & & & 0.119667 \mathrm{E}+01 & 0.246212 \mathrm{E}+01 & 0.966066 \mathrm{E}-01\end{array}$

$\begin{array}{llll}2 & 4 & 64 & 1\end{array}$

COM FORMAT (4I5)

COM INUEG $=2$ : GROUP NUMBER

COM

$\mathrm{COM}$

COM

CON

$\operatorname{COM}$

COM

COM

COM

COY

COM

COM

COM

COM

COM

COM

IEGTYP $=4:$ ELEMENT TYPE --- EQUTVALENT TO PATR
IGREL $=64:$ NUMBER OF ELEMENTS IN THIS GROUP

ISHELL $=1:$ SHELL ELEMENT FLAG

$0=$ VOLULE OR AXISYAMTRIC ELEYENT GROUP

1 = SHELL ELEUENT GROUP
$\begin{array}{llll}2 & 8 & 0 & 300\end{array}$
$0.500000 \mathrm{E}+00$
$0.700000 \mathrm{E}+02$
$0.100000 \mathrm{E}-05$

FORNAT (4I5, 3E15.6)

IELNUM $=2$ : ELEMENT NUMBER

ISUBEL $=8:$ NUMBER OF SUBELEMENTS

MATINP $=0$ : MATERIAL NUMBER FOR VOLUME FLAW ANALYSIS

MAT2 $=300$ : MATERIAL NUMBER FOR SURFACE FLAW ANALYSIS

ELVOL $=.50000:$ ELEMENT AREA

ELTEMP $=70.0$ : ELEMENT TEMPERATURE

ELTHIC $=1.0 \mathrm{E}-6 \quad:$ ELEMENT THICKNESS

$1 \quad 0.385802 \mathrm{E}-01 \quad 0.700000 \mathrm{E}+02 \quad-0.300001 \mathrm{E}+03 \quad-0.125358 \mathrm{E}-06$

$0.202518 \mathrm{E}-06$

COM FORMAT $(\mathrm{I} 5,5 \mathrm{E} 15.6)$

COM
COM
COM
COM

ISUNUM = 1 : SUBELEMENT NUUBER

SUBVOL $=.03858 \quad:$ SUBELEMENT AREA

SUBTEM $=70.0$ : SIBELEMENT TEMPERATURE

$\operatorname{SSTR}(L), L=1,3$

: STRESSES

$\sigma_{x}$
$0.617284 \mathrm{E}-01$
$0.700000 \mathrm{E}+02$
$0.700000 \mathrm{E}+02$
$0.700000 E+02$
$0.700000 E+02$
$0.700000 \mathrm{E}+02$
$0.700000 \mathrm{E}+02$
$0.700000 E+02$
$0.700000 \mathrm{E}+02$
$0.100000 \mathrm{E}+01$
$0.700000 E+02$
$0.700000 \mathrm{E}+02$
$0.771605 \mathrm{E}-01$
$10.771605 \mathrm{E}-01$
$-0.300001 E+03$
$-0.300001 \mathrm{E}+03$
$-0.300001 E+03$
$-0.300001 \mathrm{E}+03$
$-0.300001 \mathrm{E}+03$
$-0.300001 E+03$
$-0.300001 \mathrm{E}+03$
$-0.300001 \mathrm{E}+03$
$0.700000 \mathrm{E}+02$
$-0.166806 \mathrm{E}+03$
$-0.166806 \mathrm{E}+03$

.

$\begin{array}{ll}5 & 0.987654 \mathrm{E}-01 \\ 6 & 0.617284 \mathrm{E}-01 \\ 7 & 0.385802 \mathrm{E}-01 \\ 8 & 0.617284 \mathrm{E}-01 \\ 9 & 0.385803 \mathrm{E}-01\end{array}$ $\sigma_{\mathbf{y}}$

$-0.341787 \mathrm{E}-06$

$-0.558216 \mathrm{E}-06$

$-0.335760 \mathrm{E}-06$

$0.868183 \mathrm{E}-07$

$0.508388 \mathrm{E}-06$

$-0.546161 \mathrm{E}-06$

$0.515426 \mathrm{E}-06$

0.157701E-05

$0.100000 \mathrm{E}-05$

$-0.823880 \mathrm{E}-06$

$0.719767 \mathrm{E}-06$
$0.765522 \mathrm{E}-06$

$0.132853 \mathrm{E}-05$

$0.251547 \mathrm{E}-06$

$0.837670 \mathrm{E}-06$

$0.142379 \mathrm{E}-05$

$0.300575 \mathrm{E}-06$

$0.809818 \mathrm{E}-06$

0.151906E-05

0. 366658E-06

$-0.230518 \mathrm{E}-0 \mathrm{~B}$ 


\section{REFERENCES}

Barnett, R.L., Connors, C.L., Hermann, P.C., and Wingfield, J.R., 1967, "Fracture of Brittle Materials Under Transient Mechanical and Thermal Loading," U.S. Air Force Flight Dynamics Laboratory, AFDL-TR-66-220. (NTIS AD-649978).

Batdorf. S.B., and Crose, J.G., 1974, "A Statistical Theory for the Fracture of Brittle Structures Subjected to Nonuniform Polyaxial Stresses," Journal of Applied Mechanics," Vol. 41, pp. 459-464.

Batdorf. S.B., and Heinisch, H.L.Jr., 1978, “Weakest Link Theory Reformulated for Artbitrary Fracture Criteria," Journal of the American Ceramic Society, Vol. 61, pp. 355-358.

Bathe, K.J., 1982, Finite Element Procedures in Engineering Analysis, Prentice-Hall, Englewood Cliffs, New Jersey.

Erdogan, F., and Sih, G.C., 1963, "Crack Extention in Plates Under Plane Loading and Transverse Shear," Journal of Basic Engineering, Vol. 85, pp. 519-527.

Freudenthal, A.M., 1968, "Statistical Approach to Brittle Fracture," Fracture, Vol. 2: An Advanced Treatise, Mathematical Fundamentals, H. Liebowitz, ed., Academic Press, pp. 591-619.

Hellen, T.K., and Blackburn, W.S., 1975, "Calculation of Stress Intensity Factors for Combined Tensile and Shear Loading," International Journal of Fracture, Vol. 11, pp. 605-613.

Nemeth, N.N., Manderscheid, J.M., and Gyekenyesi, J.P., 1989, “Designing Ceramic Components with the CARES Computer Program," American Ceramic Society Bulletin, Vol. 68, pp. 2064-2072.

Nemeth, N.N., Manderscheid, J.M., and Gyekenyesi, J.P., 1990, “Ceramics Analysis and Reliability Evaluation of Structures (CARES). User's and Programmer's Manual," NASA TP-2916.

Palaniswamy, K., and Knauss, W.G., 1978, "On the Problem of Crack Extention in Brittle Solids Under General Loading," Mechanics Today, Vol. 4, pp. 87-148.

Sih, G.C., 1974, "Strain-Energy-Density Factor Applied to Mixed-

Mode Crack Problems," International Journal of Fracture, Vol. 10, pp. 305-321.

Shetty, D.K., 1987, “Mixed-Mode Fracture Criteria for Reliability Analysis and Design of Structural Ceramics," Journal of Engineering for Gas Turbines and Power, Vol. 109, pp. 282-289.

Weibull, W.A., 1939a, "A Statistical Theory of the Strength of Materials," Ingenoirs Vetenskaps Akadanien Handlinger, No. 151.

Weibull, W.A., 1939b, “The Phenomenon of Rupture in Solids,” Ingenoirs Vetenskaps Akadanien Handlinger, No. 153. 
TABLE 1.-FAILURE PROBABILITIES FOR THE :

WELFEP TEST CASES

\begin{tabular}{|c|c|c|c|c|c|}
\hline \multirow{2}{*}{\multicolumn{2}{|c|}{$\begin{array}{l}\text { Fracture } \\
\text { criteria }\end{array}$}} & \multirow[t]{2}{*}{ Mesh } & \multicolumn{3}{|c|}{$P_{f}$} \\
\hline & & & CARES 2 & CARES 3.0 & $\begin{array}{c}\text { Analytical } \\
\text { colution }\end{array}$ \\
\hline \multicolumn{6}{|c|}{ 1-Pure bending by prescribed displacement: } \\
\hline \multirow[t]{2}{*}{ PIA } & Volume & $\begin{array}{l}\text { Coarse } \\
\text { Fine }\end{array}$ & $\begin{array}{r}0.1054 \\
.1278 \\
\end{array}$ & $\begin{array}{r}0.1337 \\
.1363 \\
\end{array}$ & 0.1364 \\
\hline & Surface & $\begin{array}{l}\text { Coarse } \\
\text { Fine }\end{array}$ & $\begin{array}{r}0.7623 \\
.7646\end{array}$ & $\begin{array}{r}0.7677 \\
.7691 \\
\end{array}$ & 0.7691 \\
\hline \multirow[t]{2}{*}{ NSA } & Volume & $\begin{array}{l}\text { Coarue } \\
\text { Fine } \\
\end{array}$ & $\begin{array}{r}0.1053 \\
.1278 \\
\end{array}$ & $\begin{array}{r}0.1336 \\
.1363 \\
\end{array}$ & 0.1364 \\
\hline & Surface & $\begin{array}{l}\text { Coarse } \\
\text { Fine }\end{array}$ & $\begin{array}{r}0.7524 \\
.7647\end{array}$ & $\begin{array}{r}0.7679 \\
.7693 \\
\end{array}$ & 0.7691 \\
\hline \multicolumn{6}{|c|}{ 2-Notched } \\
\hline \multirow[t]{2}{*}{ PIA } & Volume & (a) & $0.1248 \times 10^{-4}$ & $0.1304 \times 10^{-4}$ & \\
\hline & Surface & (a) & $0.1184 \times 10^{-2}$ & $0.1043 \times 10^{-2}$ & \\
\hline \multirow[t]{2}{*}{ NSA } & Volume & (a) & $0.1340 \times 10^{-4}$ & $0.1421 \times 10^{-4}$ & \\
\hline & Surface & (a) & $0.1209 \times 10^{-2}$ & $0.1065 \times 10^{-2}$ & \\
\hline \multicolumn{6}{|c|}{ 3-Pure toraion by prescribed displacements } \\
\hline \multirow[t]{2}{*}{ PIA } & Volume & (a) & 0.1892 & 0.1933 & 0.1933 \\
\hline & Surface & (a) & 0.4891 & 0.4891 & 0.4891 \\
\hline \multirow[t]{2}{*}{ NSA } & Volume & (a) & 0.1371 & 0.1402 & \\
\hline & Surface & (a) & 0.3757 & 0.3757 & \\
\hline
\end{tabular}

-Mesh as defined by WELFEP proposals. 
TABLE A1.-KEY

BULK DATA

CHEXA
CORD2C
CORD2R
CORD2S
CPENTA
CQUAD4
CQUAD8
CTETRA
CTRIA3
CTRIA6
CTRIAX6
GRDSET
GRID
PSHELL
PSOLID
TEMP
TEMPD

TABLE A2.-MSC/NASTRAN SUPPORTED ELEMENT TYPES

(Shell elements should be defined to have membrane properties (i.e., no bending or transverse ebear) and be very thin (i.e., 1.E-06) so as not to contribute edditional stiffness.]

\begin{tabular}{|l|l|c|c|}
\hline \multirow{3}{*}{ Solid } & $\begin{array}{c}\text { Element } \\
\text { type }\end{array}$ & $\begin{array}{c}\text { Number } \\
\text { of nodes }\end{array}$ & $\begin{array}{c}\text { Number of } \\
\text { ubelements } \\
\text { (if divided) }\end{array}$ \\
\cline { 2 - 4 } & HEXA & $\begin{array}{c}8-19 \\
20\end{array}$ & $\begin{array}{c}8 \\
27\end{array}$ \\
\cline { 2 - 4 } & PENTA & $\begin{array}{c}6-14 \\
15\end{array}$ & $\begin{array}{c}6 \\
9\end{array}$ \\
\cline { 2 - 5 } & TETRA & $\begin{array}{c}4-9 \\
10\end{array}$ & $\begin{array}{c}1 \\
4\end{array}$ \\
\hline \multirow{3}{*}{ Shell } & QUAD4 & 4 & 1 \\
\cline { 2 - 5 } & QUAD8 & $4-7$ & 4 \\
& & 8 & 9 \\
\cline { 2 - 5 } & TRLA3 & 3 & 1 \\
\cline { 2 - 5 } & TRLA6 & $3-5$ & 1 \\
& & 6 & 3 \\
\hline \multirow{2}{*}{ Axisymmetric } & TRLAX6 & $3-5$ & 1 \\
& & 6 & 3 \\
\hline
\end{tabular}




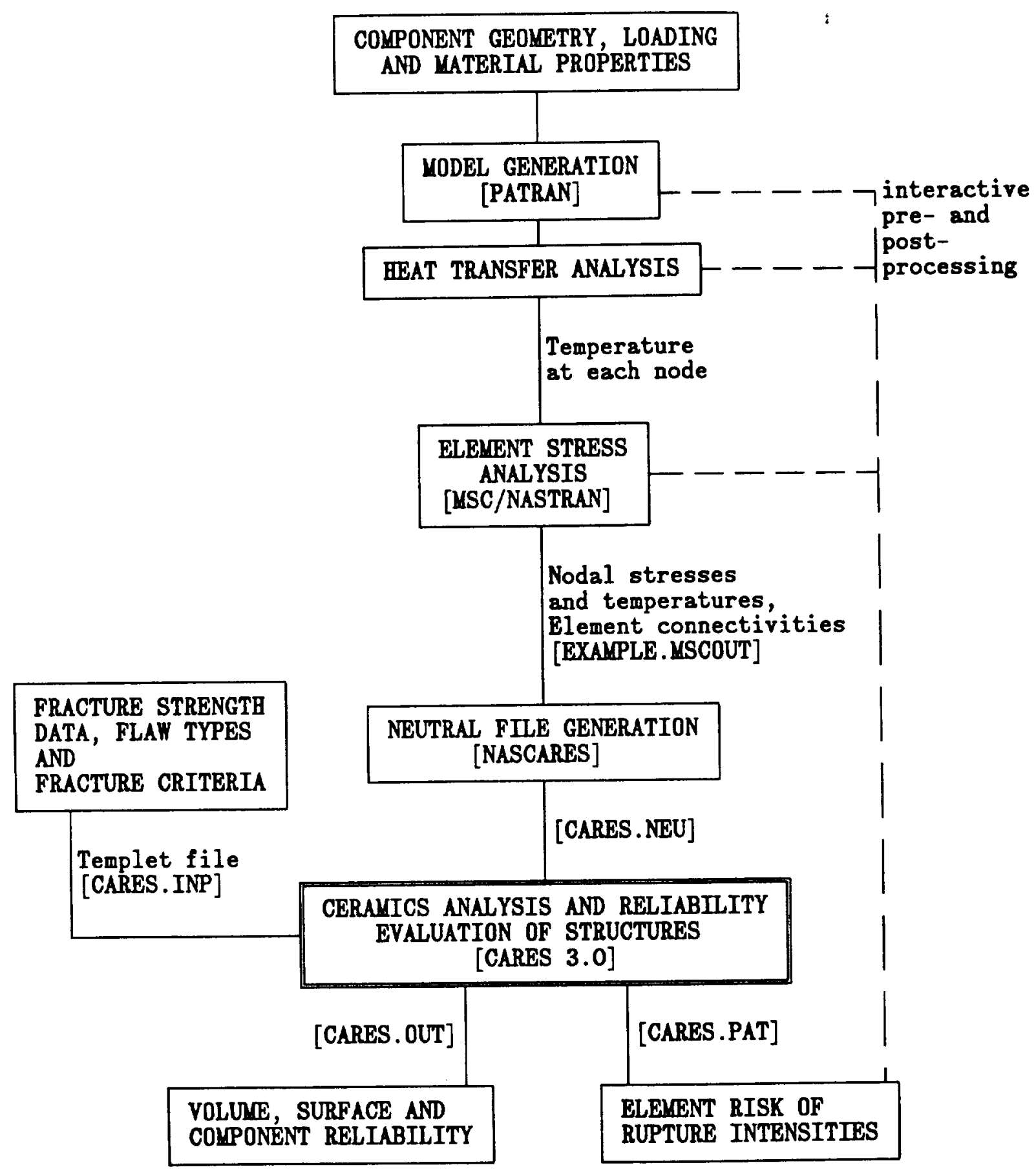

Figure A1 - Block diagram for the analysis and fast-fracture reliability evaluation of ceramic components. This analysis includes the CARES integrated design program, MSC/NASTRAN finite element analysis and PATRAN PLUS preand post-processing. 


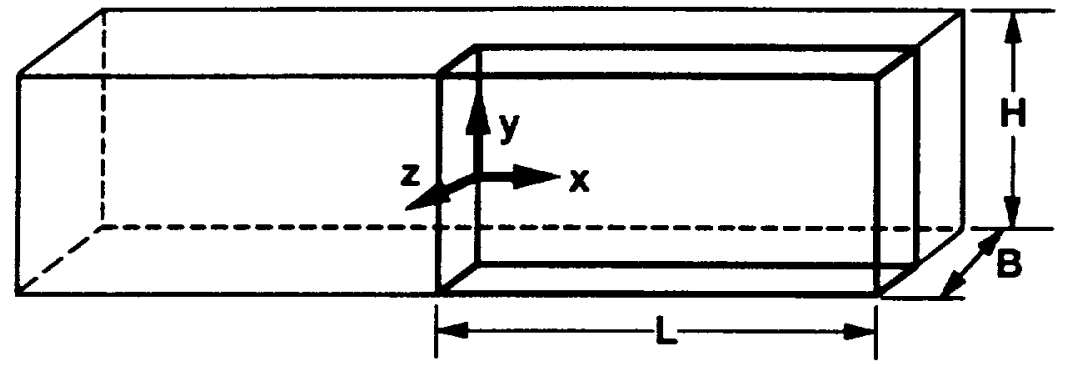

$$
\begin{aligned}
& \text { Data } \\
& L=10.0 \mathrm{~mm} \\
& H=4.0 \mathrm{~mm} \\
& B=1.0 \mathrm{~mm} \\
& m=15.0 \\
& \sigma_{o v}=362.4 \mathrm{MPa} \times \mathrm{mm}^{0.200} \\
& \sigma_{o s}=362.4 \mathrm{MPa} \times \mathrm{mm}^{0.133}
\end{aligned}
$$

Figure 1.-Pure bending by prescribed displacements. 


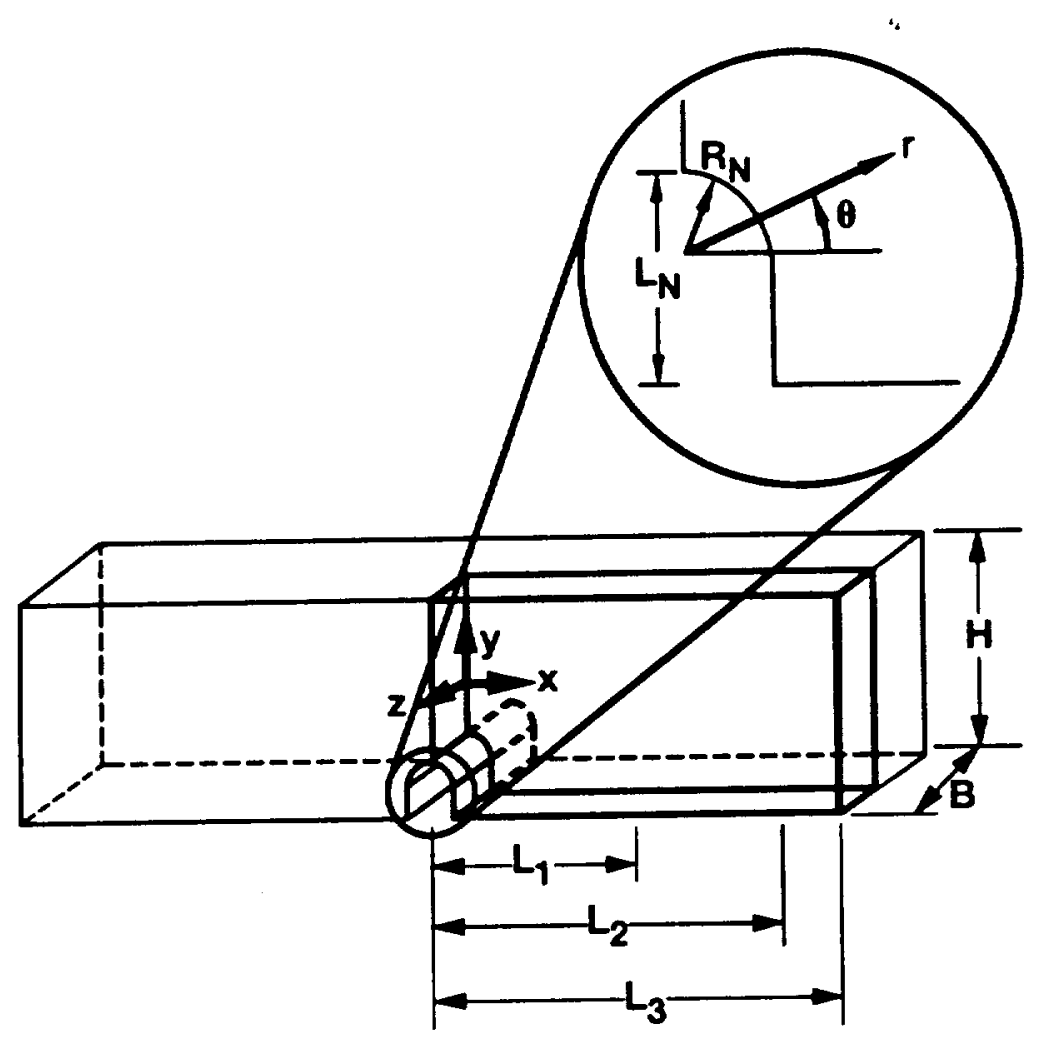

$$
\begin{aligned}
& \text { Data } \\
& L_{1}=10.0 \mathrm{~mm} \\
& L_{2}=20.0 \mathrm{~mm} \\
& L_{3}=22.5 \mathrm{~mm} \\
& H=4.0 \mathrm{~mm} \\
& B=1.0 \mathrm{~mm} \\
& m=15.0 \\
& \sigma_{\text {ov }}=1035.6 \mathrm{MPa} \times \mathrm{mm}^{0.200} \\
& \sigma_{\text {os }}=1035.6 \mathrm{MPa} \times \mathrm{mm}^{0.133} \\
& L_{N}=1.0 \mathrm{~mm} \\
& R_{N}=0.5 \mathrm{~mm}
\end{aligned}
$$

Figure 2.-Notched beam in 4-pt bend. 


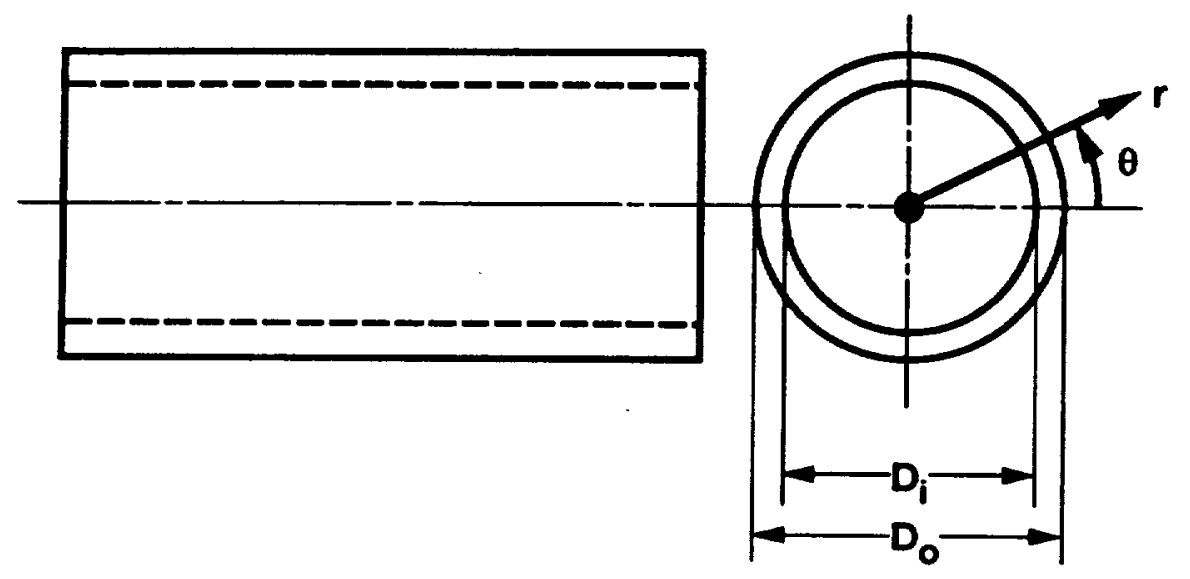

Data

$\mathrm{L}=12.5 \mathrm{~mm}$

$D_{i}=10.0 \mathrm{~mm}$

$D_{0}=12.0 \mathrm{~mm}$

$m=15.0$

$\sigma_{o v}=155.3 \mathrm{MPa} \times \mathrm{mm}^{0.200}$

$\sigma_{o s}=155.3 \mathrm{MPa} \times \mathrm{mm}^{0.133}$

Figure 3.-Pure torsion by prescribed displacements. 
Public reporting burden for this collection of information is estimated to average 1 hour per response, including the time for reviewing instructions, searching existing data sources. gathering and maintaining the data needed, and completing and reviewing the collection of intormation. Send comments regarding this burden estimate or any other aspect of this collection of intormation, including suggestions for reducing this burden, to Washington Headquarters Services, Directorale for information Operations and Reports, 1215 Jefferson Davis Highway. Sute 1204, Arlington. VA 22202-4302, and to the Otfice of Management and Budget, Paperwork Reduction Project, (0704-0188). Washington, DC 20503.
1. AGENCY USE ONLY (Leave blank)
2. REPORT DATE
September 1992
3. REPORT TYPE AND DATES COVERED
Technical Memorandum

4. TITLE AND SUBTITLE

Ceramic Component Reliability With the Restructured NASA/Cares

Computer Program

6. AUTHOR(S)

Lynn M. Powers, Alois Starlinger, and John P. Gyekenyesi

WU-505-63-5B

7. PERfoRming ORganization NAME(S) ANO ADDAESS(ES)

8. PERFoRMING ORGANIZATION REPORT NUMBER

National Aeronautics and Space Administration

Lewis Research Center

Cleveland, Ohio 44135-3191

E-6797

9. SPONSORING/MONITORING AGENCY NAMES(S) AND ADDRESS(ES)

10. SPONSORING/MONITORING AGENCY REPORT NUMBER

National Aeronautics and Space Administration

Washington, D.C. 20546-0001

NASA TM-105856

11. SUPPLEMENTARY NOTES

Prepared for the 37th International Gas Turbine and Aeroengine Congress sponsored by the American Society of Mechanical Engineers, Cologne, Germany, June 1-4, 1992. Lynn M. Powers, Cleveland State University, Department of Civil Engineering, Cleveland, Ohio 44115, and Alois Starlinger and John P. Gyekenyesi, NASA Lewis Research Center, Cleveland, Ohio. Responsible person, Lynn M. Powers, (216) 433-8374.

12. DISTRIBUTIONIAVAILABILITY STATEMENT

12b. DISTRIBUTION CODE

Unclassified - Unlimited

Subject Category 39

13. ABSTRACT (Maximum 200 words)

The Ceramics Analysis and Reliability Evaluation of Structures (CARES) integrated design program on statistical fast fracture reliability of monolithic ceramic components is enhanced to include the use of a neutral data base, twodimensional modeling and variable problem size. The data base allows for the efficient transfer of element stresses, temperatures and volumes/areas from the finite element output to the reliability analysis program. Elements are divided to insure a direct correspondence between the subelements and the Gaussian integration points. Twodimensional modeling is accomplished by assessing the volume flaw reliability with shell elements. To demonstrate the improvements in the algorithm, example problems are selected from a round-robin conducted by WELFEP (WEakest Link failure probability prediction by Finite Element Postprocessors).

14. SUBJECT TERMS

Ceramic design; Reliability; CARES; Fast fracture; Weakest link theory; Weibull; Batdorf; Finite element analysis; MSC/NASTRAN; ANSYS; ABAQUS

\begin{tabular}{|c|c|c|c|}
\hline $\begin{array}{c}\text { 17. SECURIT CLASSIFICATION } \\
\text { OF REPOAT } \\
\text { Unclassified }\end{array}$ & $\begin{array}{c}\text { 18. SECURITY CLASSIFICATION } \\
\text { OF THIS PAGE } \\
\text { Unclassified }\end{array}$ & $\begin{array}{c}\text { 19. SECURTY CLASSIFICATION } \\
\text { OF ABSTRACT } \\
\text { Unclassified }\end{array}$ \\
\hline
\end{tabular}


National Aeronautics and Space Administration

Lewis Research Center

Cleveland, Ohio 44135

Oriticlal Busineas

Penelty for Private Use 8300
FOURTH CLASS MAIL

ADDRESS CORAECTIN REQUESTED

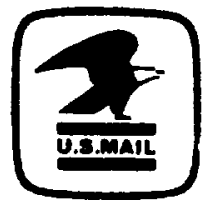

Poslage and Fees Paid

National Aeronaulics and

Space Adminisiralion

NASA 451 
